\title{
A PROSPECTIVE STUDY TO ANALYSE THE SIDE EFFECTS OF OLMESARTAN MEDOXOMIL AND ENALAPRIL IN HYPERTENSIVE SUBJECTS
}

\author{
PARMINDERPAL SINGH ${ }^{1}$, KIRANJIT ${ }^{2 *}$ \\ ${ }^{1}$ Department of General Medicine, GMC and Rajindra Hospital, Patiala, Punjab, India. ${ }^{2}$ Department of Pulmonary Medicine, GGS Medical \\ College, Faridkot, Punjab, India. Email: sidhukiranjit@yahoo.com \\ Received: 24 February 2018, Revised and Accepted: 31 July 2018
}

\section{ABSTRACT}

Objective: The present study was aimed to analyze the side effects of olmesartan medoxomil and enalapril in hypertensive subjects.

Methods: The study consisted of newly diagnosed hypertension categorized according to $7^{\text {th }}$ report of Joint National Commission on prevention, detection, evaluation, and treatment of high blood pressure. The subjects were divided into two groups. The Group A subjects received olmesartan, and Group B subjects received enalapril. Pressure was recorded both in supine and sitting positions. The appearance of side effects was observed in the follow-up, i.e., dry cough, headache, postural hypotension, angioedema, dizziness, skin rashes, taste alterations, and urticaria. A statistical data were prepared on the basis of information obtained and analyzed thoroughly for antihypertensive effects and side effects of olmesartan and enalapril. SPSS software was used for analysis.

Results: There was observed an increase in the incidence of taste alteration with drug therapy in Group B (Enalapril). There was observed an increase in the incidence of postural hypotension with drug therapy in both groups. In Group A (Olmesartan), the incidence of postural hypotension at the beginning of trial, 4 weeks, and 8 weeks was $0 \%, 2 \%$, and $2 \%$, respectively. In Group A (Olmesartan), there was no incidence of a headache at the beginning of trial, at 4 weeks and 8 weeks.

Conclusion: From the study, it can be concluded that both olmesartan and enalapril are effective in Stage I and Stage II hypertension, but olmesartan is tolerated well with lesser side effects.

Keywords: Coronary, Hypertension, Postural.

(C) 2018 The Authors. Published by Innovare Academic Sciences Pvt Ltd. This is an open access article under the CC BY license (http://creativecommons. org/licenses/by/4. 0/) DOI: http://dx.doi.org/10.22159/ajpcr.2018.v11i12.25460

\section{INTRODUCTION}

Hypertension is the most important modifiable risk factor for coronary heart disease (the leading cause of death in North America), stroke (the third leading cause), congestive heart failure, end-stage renal disease, and peripheral vascular disease. Chobanian et al. 2003 studied that hypertension or high blood pressure is a chronic medical condition in which systemic arterial blood pressure is elevated, which prompts increased visits to the primary health-care providers. It is a common treatable disease which often leads to lethal complications if left untreated [1]. The relationship between blood pressure and risk of cardiovascular disease events is continuous, consistent, and independent of other risk factors. The higher the blood pressure, the greater the chances of myocardial infarction, heart failure, stroke, and kidney disease. For individuals aged 40-70 years, each increment of $20 \mathrm{mmHg}$ in systolic blood pressure or $10 \mathrm{mmHg}$ in diastolic blood pressure doubles the risk of cardiovascular disease across the entire blood pressure range from $115 / 75$ to $185 / 115 \mathrm{mmHg}$ [2]. Cornish et al. studied ACE and found it to be ubiquitous in human body predominantly localized on endothelium throughout the body, but it is most abundantly found in lungs. It is shown to be present in both endocardial and coronary vasculature [3]. Bernstein et al. studied the protein structure of ACE which reveals active sites and sequence that ensures anchoring of proteins to the endothelial membrane. The two active sites are zinc-dependent and present on separate homologous arms of the molecule. It has been suggested that two main functions of ACE conversion of angiotensin I to angiotensin II and degradation of bradykinin correspond to two binding sites of enzymes. The reninangiotensin system or the renin-angiotensin aldosterone system is a hormone system that regulates blood pressure and water (fluid) balance, leading to raised blood volume, and raised blood pressure.
The system can be activated when there is a loss of blood volume or a drop in blood pressure (such as in hemorrhage). This loss of pressure is interpreted by baroreceptors in the carotid sinus. In alternative fashion, a decrease in the filtrate $\mathrm{NaCl}$ concentration and/or decreased filtrate flow rate will stimulate the macula densa to release renin [4]. Angiotensin receptor blockers came into limelight and owned the vital place as antihypertensive agents because of the side effects and low efficacy profile of diuretics, beta blockers, and CCB's. The present study was aimed to analyze the side effects of olmesartan medoxomil and enalapril in hypertensive subjects.

\section{METHODS}

The study consisted of newly diagnosed hypertension categorized according to $7^{\text {th }}$ report of the Joint National Commission on prevention, detection, evaluation, and treatment of high blood pressure. The patients were selected from Outpatient Department and wards of the Medicine Department of Rajindra Hospital, Patiala. The study was approved by the Institutional Ethical Board, and all the subjects were informed about the study, and written consent was obtained from all. Pregnant or lactating mothers and patients with chronic renal failure were excluded from the study. The subjects were divided into two groups. The Group A subjects received olmesartan, and Group B subjects received enalapril. The pressure was recorded both in supine and sitting position. Postural change in BP was also noted. The bladder was inflated quickly to a pressure of $20 \mathrm{mmHg}$ above the systolic level, as recognized by the disappearance of radial pulse. Korotkoff phase $\mathrm{V}$ was taken as diastolic BP. At least two recordings were taken at interval of $10 \mathrm{~min}$. If the readings varied by more than $5 \mathrm{mmHg}$, additional reading was taken until two were close. The patients were followed up at weekly intervals for 8 weeks. The dose was escalated if the response 
shown by the patients after 2 weeks were suboptimal. The appearance of side effects was observed in the follow-up, i.e., dry cough, headache, postural hypotension, angioedema, dizziness, skin rashes, taste alterations, and urticaria. A statistical data were prepared on the basis of information obtained and analyzed thoroughly for antihypertensive effects and side effects of olmesartan and enalapril. SPSS software was used for analysis.

\section{RESULTS}

A total of 100 subjects were enrolled in the study, of which in Group A, there were 62\% males and 38\% females. In Group B, there were 44\% males and $56 \%$ females.

Table 1 shows the comparison of incidence of dry cough between the two groups. There was observed increase in incidence of dry cough with drug therapy in Group B (Enalapril). In Group A (Olmesartan), the incidence of dry cough at the beginning of trial, 4 weeks, and 8 weeks was $0 \%, 2 \%$, and $2 \%$, respectively. In Group B (Enalapril), the incidence of dry cough at the beginning of trial, 4 weeks, and 8 weeks was $0 \%$, $14 \%$, and $14 \%$, respectively. On comparing the incidence of dry cough in two groups at various time intervals, i.e., between 0 and 4 and 0 and 8 weeks, the figure shows greater increase in Group B (enalapril) than in Group A (Olmesartan) which was statistically significant $(P<0.05)$.

Table 2 shows the comparison of the incidence of skin rashes between the two groups. There was observed increase in incidence of skin rashes with drug therapy in Group B (Enalapril). In Group A (Olmesartan), there was no incidence of skin rash at the beginning of trial, 4 weeks, and 8 weeks. In Group B (Enalapril), the incidence of skin rashes at the beginning of trial, 4 weeks, and 8 weeks was $0 \%, 4 \%$, and $4 \%$, respectively. On comparing the incidence of skin rashes in two groups at various time intervals, i.e., between 0 and 4 and 0 and 8 weeks, the figure shows greater increase in Group B (Enalapril) than in Group A (Olmesartan), but it was statistically non-significant ( $p>0.05$ ).

Table 3 shows the comparison of the incidence of angioedema between the two groups. There was observed increase in incidence of angioedema with drug therapy in Group B (Enalapril). In Group A (Olmesartan), there was no incidence of angioedema at the beginning of trial, 4 weeks, and 8 weeks. In Group B (Enalapril), the incidence of angioedema at the beginning of trial, 4 weeks, and 8 weeks was $0 \%$, $4 \%$, and $4 \%$, respectively. On comparing the incidence of angioedema in two groups at various time intervals, i.e., between 0 and 4 and 0 and 8 weeks, the figure shows greater increase in Group B (enalapril) than in Group A (Olmesartan), but it was statistically non-significant $(\mathrm{p}>0.05)$.

Table 4 shows the alteration in taste sensation between the two groups. There was observed increase in the incidence of taste alteration with drug therapy in Group B (Enalapril). In Group A (Olmesartan), there was no incidence of taste alteration at the beginning of trial, 4 weeks, and 8 weeks. In Group B (Enalapril), the incidence of taste alteration at the beginning of trial, 4 weeks, and 8 weeks was $0 \%, 4 \%$, and $4 \%$, respectively. On comparing the incidence of taste alteration in two

Table 1: Comparison of incidence of dry cough in Group A (olmesartan) with Group B (enalapril) at different time intervals

\begin{tabular}{lllll}
\hline $\begin{array}{l}\text { Dry } \\
\text { cough }\end{array}$ & Period (0-4 weeks) & & & Period (0-8 weeks) \\
\cline { 2 - 3 } & Group A (Olmesartan) & Group B (Enalapril) & & Group A (Olmesartan) \\
\hline Present & 1 & 7 & 1 & Group B (Enalapril) \\
Absent & 49 & 43 & 49 & 7 \\
Total & 50 & 50 & & 50 \\
p value & $<0.05(S)$ & & $<0.05(S)$ \\
\hline
\end{tabular}

Table 2: Comparison of incidence of skin rashes in Group A (olmesartan) with Group B (enalapril) at different time intervals

\begin{tabular}{lllllll}
\hline Dry cough & \multicolumn{2}{l}{ Period (0-4 weeks) } & & Period (0-8 weeks) & \\
\cline { 2 - 3 } & Group A (Olmesartan) & Group B (Enalapril) & & Group A (Olmesartan) & Group B (Enalapril) \\
\hline Present & 0 & 2 & 0 & 50 & 2 \\
Absent & 50 & 50 & & 50 & 58 \\
Total & 50 & 50 & & $p>0.05(\mathrm{NS})$ & \\
$\mathrm{p}$ value & $\mathrm{p}>0.05(\mathrm{NS})$ & & & \\
\hline
\end{tabular}

Table 3: Comparison of incidence of angioedema in Group A (olmesartan) with Group B (enalapril) at different time intervals

\begin{tabular}{|c|c|c|c|c|}
\hline \multirow[t]{2}{*}{ Dry cough } & \multicolumn{2}{|l|}{ Period (0-4 weeks) } & \multicolumn{2}{|l|}{ Period (0-8 weeks) } \\
\hline & Group A (Olmesartan) & Group B (Enalapril) & Group A (Olmesartan) & Group B (Enalapril) \\
\hline Present & 0 & 2 & 0 & 2 \\
\hline Absent & 50 & 48 & 50 & 48 \\
\hline Total & 50 & 50 & & 50 \\
\hline $\mathrm{p}$ value & $\mathrm{p}>0.05$ (NS) & & $\mathrm{p}>0.05$ (NS) & \\
\hline
\end{tabular}

Table 4: Comparison of incidence of taste alteration in Group A (olmesartan) with Group B (enalapril) at different time intervals

\begin{tabular}{llllll}
\hline Dry cough & Period (0-4 weeks) & & Period (0-8 weeks) & \\
\cline { 2 - 3 } & Group A (Olmesartan) & Group B (Enalapril) & & Group A (Olmesartan) & Group B (Enalapril) \\
\hline Present & 0 & 2 & 0 & 50 & 2 \\
Absent & 50 & 50 & & 50 & 58 \\
Total & 50 & & & $p>0.05$ (NS) & 50 \\
p value & $\mathrm{p}>0.05(\mathrm{NS})$ & &
\end{tabular}


groups at various time intervals, i.e., between 0 and 4 and 0 and 8 weeks, the figure shows greater increase in Group B (enalapril) than in Group A (Olmesartan), but it was statistically non-significant $(\mathrm{p}>0.05)$.

Table 5 shows the incidence of postural hypotension between both the groups. There was observed increase in incidence of postural hypotension with drug therapy in both groups. In Group A (Olmesartan), the incidence of postural hypotension at the beginning of trial, 4 weeks, and 8 weeks was $0 \%, 2 \%$, and 2\%, respectively. In Group B (Enalapril), the incidence of postural hypotension at the beginning of trial, 4 weeks, and 8 weeks was $0 \%, 2 \%$, and $2 \%$, respectively. On comparing the incidence of postural hypotension in two groups at various time intervals, i.e., between 0 and 4 and 0 and 8 weeks, the figure shows an increase in both Group A (Olmesartan) and Group B (Enalapril), but it was statistically non-significant $(\mathrm{p}>0.05)$.

Table 6 shows the incidence of headache among both the groups. There was observed increase in incidence of headache with drug therapy in Group B (Enalapril). In Group A (Olmesartan), there was no incidence of headache at the beginning of trial, 4 weeks, and 8 weeks. In Group B (Enalapril), the incidence of headache at the beginning of trial, 4 weeks, and 8 weeks was $0 \%, 8 \%$, and $8 \%$, respectively. On comparing the incidence of headache in two groups at various time intervals, i.e., between 0 and 4 and 0 and 8 weeks, the figure shows greater increase in Group B (enalapril) than in Group A (Olmesartan) which was statistically significant $(\mathrm{p}<0.05)$.

Table 7 shows the comparison of urticaria amongst both the groups. There was observed increase in the incidence of urticaria with drug therapy in both groups. In Group A (Olmesartan), the incidence of urticaria at the beginning of trial, 4 weeks, and 8 weeks was $0 \%, 2 \%$, and 2\%, respectively. In Group B (Enalapril), the incidence of urticaria at the beginning of trial, 4 weeks, and 8 weeks was $0 \%$, $4 \%$, and $4 \%$, respectively. On comparing the incidence of urticaria in two groups at various time intervals, i.e., between 0 and 4 and 0 and 8 weeks, the figure shows greater increase in Group B (enalapril) than in Group A (Olmesartan), but it was statistically non-significant ( $p>0.05$ ).

\section{DISCUSSION}

The ever increasing introduction of new therapeutic agent means that the potential for drug interaction is likely to escalate. The angiotensinconverting enzyme (ACE) inhibitors and angiotensin receptor blockers offer one of the newest approaches to the management of patients with high blood pressure. There was observed increase in the incidence of a dry cough with drug therapy in both the groups. On comparing the incidence of dry cough in both the groups at various time intervals, i.e., between 0 and 4 and 0 and 8 weeks, the figures show greater increase in Group B (Enalapril), i.e., 0\%, 14\%, and 14\% at beginning of trial, 4 weeks, and 8 weeks, respectively, than in Group A (Olmesartan), i.e., $0 \%$, $4 \%$, and $4 \%$ at beginning of trial, 4 weeks, and 8 weeks, respectively, which was statistically significant $(\mathrm{p}<0.05)$. Woo and Nicholls evaluated the prevalence of cough in Chinese patients receiving ACE inhibitors and concluded that about $18 \%$ of patients developed dry cough with enalapril [5]. Yestil et al. (1994) investigated the incidence of dry cough in 1113 patients with arterial hypertension in a retrospective study and concluded that the incidence of dry cough $(7 \%)$ was higher during enalapril therapy in hypertensive patients [6]. Agostoni et al. detected ACE inhibitor-associated angioedema in 39 subjects (17\%) of 231 consecutive patients examined in the 5 years at the outpatient clinic which was significant [7]. Cicardi et al. described ACE inhibitor-related angioedema in a retrospective analysis of 64 consecutive patients (January 1993-June 2002) presenting with angioedema onset while receiving treatment with an ACE inhibitor and concluded that only a small percentage of patients with ACE inhibitor-related angioedema continue with this symptom when switched to an ARB [8]. Hence, the incidence of angioedema in our designed study was comparable with previously done studies. Puchler et al. (2001) compared the tolerability of olmesartan medoxomil $10 \mathrm{mg}, 20 \mathrm{mg}$, and $40 \mathrm{mg}$ with placebo and observed that postural hypotension was observed in $0.1 \%$ cases on $20 \mathrm{mg}$ olmesartan and in none of the cases on $10 \mathrm{mg}$ and 40 $\mathrm{mg}$ of olmesartan [9]. Hence, the incidence of postural hypotension in our designed study was comparable with previously done studies. Gomez et al. studied the effect of enalapril in the treatment of mild to moderate hypertension. The study concluded that one of the common adverse effects of enalapril is a headache which occurred in $5.2 \%$ of

Table 5: Comparison of incidence of postural hypotension in Group A (olmesartan) with Group B (enalapril) at different time intervals

\begin{tabular}{llclc}
\hline Dry cough & Period (0-4 weeks) & & Period (0-8 weeks) \\
\cline { 2 - 3 } & Group A (olmesartan) & Group B (enalapril) & & Group A (olmesartan) \\
\hline Present & 1 & 1 & 1 \\
Absent & 49 & 49 & 49 \\
Total & 50 & 50 & 50 \\
p value & $\mathrm{p}>0.05(\mathrm{NS})$ & & $\mathrm{p}>0.05(\mathrm{NS})$ \\
\hline
\end{tabular}

Table 6: Comparison of incidence of headache in Group A (olmesartan) with Group B (enalapril) at different time intervals

\begin{tabular}{llllll}
\hline Dry cough & Period (0-4 weeks) & & & Period (0-8 weeks) & \\
\cline { 2 - 3 } & Group A (Olmesartan) & Group B (Enalapril) & & Group A (Olmesartan) & Group B (Enalapril) \\
\hline Present & 0 & 4 & & & 4 \\
Absent & 50 & 46 & 50 & 48 \\
Total & 50 & 50 & & 50 & 50 \\
p value & $\mathrm{p}<0.05(\mathrm{~S})$ & & $\mathrm{p}<0.05(\mathrm{~S})$ & \\
\hline
\end{tabular}

Table 7: Comparison of incidence of urticaria in Group A (olmesartan) with Group B (enalapril) at different time intervals

\begin{tabular}{|c|c|c|c|c|}
\hline \multirow[t]{2}{*}{ Dry cough } & \multicolumn{2}{|l|}{ Period (0-4 weeks) } & \multicolumn{2}{|l|}{ Period (0-8 weeks) } \\
\hline & Group A (Olmesartan) & Group B (Enalapril) & Group A (Olmesartan) & Group B (Enalapril) \\
\hline Present & 1 & 2 & 1 & 2 \\
\hline Absent & 49 & 48 & 49 & 48 \\
\hline Total & 50 & 50 & 50 & 50 \\
\hline $\mathrm{p}$ value & $\mathrm{p}>0.05$ (NS) & & $\mathrm{p}>0.05$ (NS) & \\
\hline
\end{tabular}


cases [10]. As per a study conducted by Makani et al. [11]; a shallow dose-response curve was seen when angiotensin receptor blockers were used as monotherapy. As per a study by Yoshida and Kohzuki [12]; olmesartan is a potent and effective antihypertensive and has better organ protection action as compared to other drugs. Hypertension is the most common cardiovascular illness and is a major public health issue in developed as well as in developing countries [13]. Preventing and managing hypertension are collectively a major challenge in the art of patient care [14]

\section{CONCLUSION}

From the study, it can be concluded that both olmesartan and enalapril are effective in Stage I and Stage II hypertension, but olmesartan is tolerated well with lesser side effects. It can be concluded that $20 \mathrm{mg}$ of olmesartan once a day is as effective as $20 \mathrm{mg}$ of enalapril once a day in the treatment of Stage I and Stage II hypertension.

\section{AUTHOR'S CONTRIBUTION}

Dr. Parminderpal Singh carried out the whole study, performed the analysis and interpretation of data, and finally wrote the manuscript. The corresponding author Dr. Kiranjit contributed to guidance, review of the manuscript and made final approval of the version to be submitted.

\section{CONFLICTS OF INTEREST}

The author declared that there are no conflicts of interest.

\section{REFERENCES}

1. Chobanian AV, Bakris GL, Black HR, Cushman WC, Green LA, Izzo JL Jr, et al. Seventh report of the joint national committee on prevention, detection, evaluation, and treatment of high blood pressure. Hypertension 2003;42:1206-52.

2. Lewington S, Clarke R, Qizilbash N, Peto R, Collins R, Prospective Studies Collaboration. et al. Age-specific relevance of usual blood pressure to vascular mortality: A meta-analysis of individual data for one million adults in 61 prospective studies. Lancet 2002;360:1903-13.

3. Cornish KG, Joyner WL, Gilmore JP. Evidence for the conversion of angiotensin I to angiotensin II by the coronary microcirculation. Blood Vessels 1979; 16:241-6

4. Bernstein K, Martin BM, Bernstein EA, Linton J, Striker L, Striker G. The isolation of angiotensin converting enzyme cDNA. J Biol Chem 1988;263:1021-4.

5. Woo KS, Nicholls MG. High prevalence of persistent cough with angiotensin converting enzyme inhibitors in Chinese. Br J Clin Pharmacol 1995;40:141-4

6. Yeșil S, Yeșil M, Bayata S, Postaci N. ACE inhibitors and cough. Angiology 1994;45:805-8

7. Agostoni A, Cicardi M, Cungo M, Zingale LC, Gioffre D, Nussberger J. Angioedema due to angiotensin-converting enzyme inhibitors. Immunopharmacology 1999;44:21-5.

8. Cicardi M, Zingale LC, Bergamaschini L, Agostoni A. Angioedema associated with angiotensin-converting enzyme inhibitor use: Outcome after switching to a different treatment. Arch Intern Med 2004;164:910-3.

9. Püchler K, Nussberger J, Laeis P, Witte PU, Brunner HR. Blood pressure and endocrine effects of single doses of CS-866, a novel angiotensin II antagonist, in salt-restricted hypertensive patients. J Hypertens 1997; 15:1809-12.

10. Gomez HJ, Cirillo VJ, Smith SG $3^{\text {rd }}$. Enalapril: Benefit-to-risk ratio in hypertensive patients. J Cardiovasc Pharmacol 1990;15 Suppl 3:S26-9.

11. Makani H, Bangalore S, Supariwala A, Romero J, Argulian E, Messerli FH, et al. Antihypertensive efficacy of angiotensin receptor blockers as monotherapy as evaluated by ambulatory blood pressure monitoring: A meta-analysis. Eur Heart J 2014;35:1732-42.

12. Yoshida K, Kohzuki M. Clinical and experimental aspects of olmesartan medoxomil, a new angiotensin II receptor antagonist. Cardiovasc Drug Rev 2004:22:285-308

13. GaniyuKehinde A, Ismail AS. Assessment of antihypertensives utilization in a private teaching hospital in Nigeria. Int J Pharm Pharm Sci $2012 ; 4: 480-3$

14. Joshi UH, Ganatra TH, Desai TR, Tirgar PR. Evaluation of antihypertensive activity of Evolvulus alsinoides in adrenaline induced hypertensive rats. Int J Pharm Pharm Sci 2012;4:194-8. 